\title{
Different promoters of SHV-2 and SHV-2a $\beta$-lactamase lead to diverse levels of cefotaxime resistance in their bacterial producers
}

\author{
Andreas Podbielski*, Jutta Schönling, Beate Melzer and Gerhard HaAse \\ Institute of Medical Microbiology, Medical Faculty, Technical University (RWTH), Pauwelsstrasse 30, \\ 5100 Aachen, FRG
}

(Received 3 January 1991; revised 25 March 1991; accepted 9 April 1991)

\begin{abstract}
Clinical Klebsiella pneumoniae isolates as well as Escherichia coli transformants producing the $\beta$-lactamases SHV2 or SHV-2a demonstrate MIC values for cefotaxime of $4 \mathrm{mg} \mathrm{l}^{-1}$ or 64 to $>128 \mathrm{mg} \mathrm{I}^{-1}$, respectively. The $\beta$ lactamases differ by one possibly insignificant amino acid exchange at position number 10 of the mature protein; their kinetic parameters are rather similar. The $5^{\prime}$ untranslated regions of both corresponding genes show no homology starting 74 nucleotides upstream to the start codon. Hybridization of intragenically annealing oligonucleotides to dot-blotted serial dilutions of total cellular RNA from $E$. coli transformants harbouring these genes cloned into the same vector plasmid gave a positive signal down to $1.2 \mu \mathrm{g}(\mathrm{SHV}-2)$ and 0.32 to 0.16 $\mu \mathrm{g}$ (SHV2a), indicating a four to eight times higher amount of specific transcript in the case of SHV-2a. By primer extension analysis and $\mathrm{S} 1$ nuclease digestion the starting point of transcription was located 100 nucleotides (SHV2) and 50 nucleotides (SHV-2a) in front of the start codon. No other transcripts of different length could be detected after prolonged exposure. Northern blot analysis demonstrated the length of the $\beta$-lactamase mRNA to be about $1.6 \mathrm{~kb}$ in both cases, thus comprising a potential open reading frame downstream of the two enzymes' genes. Selective PCR amplification of both promoter regions and of the structural gene of SHV-2 and subsequent combined cloning of each of the promoters and the SHV-2 gene into pBGS19 using a BamHI restriction site introduced by three point mutations into the cloned sequences was employed to transform $E$. coli DH5 $\alpha$. The MIC value for cefotaxime of transformants harbouring the SHV-2 promoter and SHV-2 structural gene was $8 \mathrm{mg} \mathrm{l}^{-1}$, but was $64 \mathrm{mg} \mathrm{I}^{-1}$ in the case of the SHV-2a promoter and SHV-2 structural gene combination, indicating that the quantitative change of resistance to cefotaxime of SHV-2a-producing bacteria is caused solely by a significant promoter mutation.
\end{abstract}

\section{Introduction}

In the last few years an increasing number of plasmidcoded $\beta$-lactamases from members of the Enterobacteriaceae such as Escherichia coli and Klebsiella spp. have been described. Initially the investigators' attention was drawn to these bacteria because of the increased resistance of a given isolate to a newer $\beta$-lactam, e.g. a methoxyiminocephalosporin. Analysis of the mechanism of resistance most often yielded an altered $\beta$ lactamase, mainly from the groups of TEM or SHV enzymes. At present, at least 19 TEM-group and eight SHV-group $\beta$-lactamases (references summarized in: Mabilat \& Courvalin, 1990; Podbielski et al., 1991) have been characterized, many of them at the nucleotide sequence level. In all cases the genes of these enzymes

Abbreviation: PCR, polymerase chain reaction. differed in a few point mutations, leading to even fewer amino acid exchanges, with one or two of these in the pouch of the active site of the enzyme, thus in some cases affecting the enzyme's affinity for a given $\beta$-lactam compound and by this means the rate and effectivity of its hydrolysis (Labia et al., 1988; Collatz et al., 1989). Besides the possibility of reaching an increased level of resistance to recently developed $\beta$-lactams by introducing appropriate point mutations within the structural gene of the $\beta$-lactamase, there exists another mechanism of adaptation for the bacteria, namely by augmenting the rate of expression of the enzyme, a point that only a few investigators have considered. Obvious differences between $\beta$-lactamase promoters of Gram-negative bacteria are well characterized only in the case of transposonand plasmid-encoded TEM enzymes (Chen \& Clowes, 1984, 1987; Sougakoff et al., 1988; Mabilat et al., 1990). Recently, we described a variant of the SHV-2 $\beta$ - 
lactamase, SHV-2a, whose kinetic parameters with respect to different methoxyiminocephalosporins did not differ significantly from the original SHV-2 enzyme; but when SHV-2a was expressed by the natural Klebsiella pneumoniae host, the bacteria showed an increased minimum inhibitory concentration (MIC) for cefotaxime of at least $128 \mathrm{mg} \mathrm{l}^{-1}$ (Podbielski et al., 1991). Comparison of the genes and neighbouring nucleotide sequences revealed three point mutations within the gene leading to one amino acid exchange of questionable importance. Gene dosage effects could be excluded, since SHV-2 and SHV-2a appear as single-copy genes in their original hosts, as judged by hybridization experiments using intragenic probes and restriction-enzymedigested genomic and plasmid host cell DNA. In contrast, the $5^{\prime}$ untranslated regions of both genes were totally different starting 74 nucleotides upstream of the start codon, which is within the putative promoter region. Since only one research group (Arakawa et al., 1986) had tried to establish the SHV promoter sequence for the chromosomally encoded SHV-type $\beta$-lactamase LEN-1 (presumably by homology identification), we decided to characterize the SHV-2 and SHV-2a promoters experimentally and subsequently to analyse the actual strength of each promoter in order to explain the different MICs for cefotaxime of Klebsiella isolates producing these enzymes.

\section{Methods}

Bacterial strains, plasmids and media. E. coli DH5 $\alpha$ (BRL) was used as a host strain for recombinant plasmids. High-copy-number plasmid pBGS19 (Spratt et al., 1986) served as a vector plasmid. Recombinant plasmids pBP60-1-2 and pZMP1-1-1, harbouring a $2 \cdot 3 \mathrm{~kb}$ insert including the gene for SHV-2 and a $2 \cdot 2 \mathrm{~kb}$ insert including the SHV-2a gene, respectively, each cloned into pBGS18, have been described elsewhere (Kliebe et al., 1985; Podbielski et al., 1991).

DST agar (Unipath Oxoid) was used for routine culturing of bacteria. When required, it was supplemented with ampicillin $\left(50 \mathrm{mg} \mathrm{l}^{-1}\right)$ or cefotaxime $\left(2 \mathrm{mg} \mathrm{l}^{-1}\right)$. Recombinant clones were screened on $\mathrm{H}$ agar (protocol by Boehringer Mannheim) supplemented with kanamycin $\left(30 \mathrm{mg} \mathrm{l}^{-1}\right)$, X-Gal and ITPG.

MICs were assessed by the MicroScan system (Baxter) in ready-to use microtitre plates, following the protocol of the manufacturer.

Preparation of nucleic acids. Small-scale preparation of plasmid DNA was done by the method outlined by Zhou et al. (1990). In the case of DNA sequencing this method was scaled up, followed by phenol extraction and ethidium bromide/ $\mathrm{CsCl}$ density gradient centrifugation in a Beckman TLV $100 \mathrm{~K}$ rotor at 100000 r.p.m. for $3 \mathrm{~h}$. Bands containing covalently closed circular plasmid DNA were punctured and drawn off with a hypodermic syringe and ethidium bromide was extracted from these by phenol treatment. Two micrograms of this DNA suspended in TE buffer (10 mM-Tris pH 7.5, 1 mM-EDTA) was used for an individual sequencing reaction. When appropriate, single DNA fragments generated by polymerase chain reaction (PCR) amplification or restriction digests were electroeluted from agarose gels and purified by affinity chromatography on NACS-52 (BRL) according to the manufacturer's instructions. Total cellular RNA was isolated according to the protocol of Reddy et al. (1990). Concentration of RNA solutions was measured spectrophotometrically at $260 \mathrm{~nm}$.

DNA techniques. Restriction enzyme digests, DNA ligation, $1 \%$ $(w / v)$ agarose gel electrophoresis and Southern blotting by vacuum onto Biodyne B nylon membranes (Pall Bio Support) were done by conventional methods (Sambrook et al., 1989). The enzymes necessary for these procedures were purchased from Boehringer Mannheim. Transformation of $E$. coli recipients was performed as outlined by Hanahan (1983); colony blots were done according to Maas (1983). Hybridization with non-radioactively labelled oligonucleotide probes and visualization with the Photogene system (BRL) was described earlier (Podbielski et al., 1990); stringent hybridization temperatures were selected 5 to $10^{\circ} \mathrm{C}$ below the calculated melting temperature $\left(T_{\mathrm{D}}\right)$, using the oligo program (National Bioscience Inc.) for calculation. Oligonucleotides for probing, sequencing and primer extension experiments (Fig. 1) were synthesized on a Beckman 200A DNA synthesizer, eluted, deprotected and desalted following the instructions of the manufacturer. Oligonucleotides for RNA dot-blot and Northern blot hybridization were $5^{\prime}$ labelled using $\left[\gamma-{ }^{32} \mathrm{P}\right] \mathrm{ATP}$ (Amersham) according to Sambrook et al. (1989).

DNA sequencing was performed by the dideoxy chain-termination method (Sanger et al., 1977) using the $T_{7}$ sequencing kit (Pharmacia), pUC standard forward and reverse primers and $\left[\alpha^{-35}\right.$ S]dATP (Amersham) as exemplified in the instructions of the manufacturers. Sequences were analysed with the aid of the PC GENE program (IntelliGenetics) on a IBM PS-2 personal computer.

PCR was run in a Techne PHC 1 thermal cycler. The reaction volume of $100 \mu \mathrm{l}$ contained (final concentrations): $1 \mu \mathrm{g}$ template DNA, $200 \mu \mathrm{M}$-dNTPs, $1 \mu \mathrm{M}$ of each primer, $50 \mathrm{mM} \mathrm{KCl}, 10 \mathrm{mM}$-Tris pH 8.3, $1.5 \mathrm{mM}-\mathrm{MgCl}_{2}$ and $0.01 \%(\mathrm{w} / \mathrm{v})$ gelatin; it was overlaid with $100 \mu \mathrm{l}$ mineral oil, heated to $100^{\circ} \mathrm{C}$ for $5 \mathrm{~min}, 2 \mathrm{U}$ of Taq polymerase (BRL) was added and the assay was placed into the cycler where the cycling programme was immediately started. The programme consisted of 27 cycles at $94^{\circ} \mathrm{C}$ for $1 \mathrm{~min}, 55^{\circ} \mathrm{C}$ for $1 \mathrm{~min}$ and $72^{\circ} \mathrm{C}$ for $2.5 \mathrm{~min}$, followed by a final segment of $72^{\circ} \mathrm{C}$ for $7.7 \mathrm{~min}$. The mineral oil overlay was extracted with $100 \mu \mathrm{l}$ chloroform, and, if appropriate, the amplification products were analysed or prepared for further experiments by electrophoresis on a $1 \%$ agarose minigel using Tris/phosphate/EDTA as running buffer.

RNA techniques. Northern and dot-blotting of total cellular RNA onto Biodyne B nylon membrane was done as outlined by Davis et al. (1986). Hybridization of dot-blotted and Northern-blotted RNA with 5 ' radioactively labelled oligonucleotides was performed under the same conditions as hybridization with non-radioactively labelled probes (see above).

For primer extension analysis as modified from Inoue \& Cech (1985), 1 pmol oligonucleotide primer was dissolved in $5 \mu$ l hybridization buffer I ( $60 \mathrm{mM}-\mathrm{NaCl} / 50 \mathrm{mM}$-Tris $\mathrm{pH} 8 \cdot 3 / 10 \mathrm{~mm}$-DTT), and $20 \mu \mathrm{g}$ total cellular RNA dissolved in $5 \mu$ l hybridization buffer I was added. The mixture was heated to $90^{\circ} \mathrm{C}$, gradually cooled to $30^{\circ} \mathrm{C}$ over a period of $45 \mathrm{~min}$, then $1 \mu \mathrm{l} 60 \mathrm{mM}-\mathrm{MgCl}_{2}$ was added. Five microlitres of this mixture were transferred to a new tube containing $3 \mu \mathrm{l}$ $\mathrm{dCTP} / \mathrm{dGTP} / \mathrm{dTTP}$ dissolved in hybridization buffer $\mathrm{I} / 6 \mathrm{mM}-\mathrm{MgCl}_{2}$ at a final concentration of $200 \mu \mathrm{M}$ of each nucleotide, $1.5 \mu \mathrm{l}\left[\alpha^{-35} \mathrm{~S}\right] \mathrm{dATP}$ and $2 \mu \mathrm{l}(400 \mathrm{U}) \mathrm{MMTV}$ reverse transcriptase (BRL). The assay was incubated at $37^{\circ} \mathrm{C}$ for $5 \mathrm{~min}$, then $1 \mu 12 \mathrm{~mm}$-dATP was added and the incubation continued for a further $30 \mathrm{~min}$ at $37^{\circ} \mathrm{C}$. After this the reaction was stopped by adding $5 \mu \mathrm{l}$ loading buffer $(90 \%, \mathrm{v} / \mathrm{v}$, formamide/20 mM-EDTA/bromophenol blue and xylene cyanol $1 \mathrm{mg} \mathrm{m}^{-1}$ each). Before loading onto a $8 \%(\mathrm{w} / \mathrm{v})$ polyacrylamide sequencing gel with dideoxy termination sequencing reaction mixtures 
in parallel as nucleotide length markers, the primer extension reaction mixture was denatured by the conventional procedure $\left(5 \min\right.$ at $95^{\circ} \mathrm{C}$, $5 \mathrm{~min}$ on ice, spin in a centrifuge, $2 \mathrm{~min}$ at $95^{\circ} \mathrm{C}, 2 \mathrm{~min}$ on ice, spin again).

For S1 nuclease digestion mapping as modified from Aiba et al. (1981), a 1672 bp BamHI-NotI DNA fragment and a 1076 bp PstINotI DNA fragment from the cloned SHV-2a and SHV-2 genes, respectively, both containing 146 intragenic bp and the adjacent $5^{\prime}$ untranslated regions, were separated on $1 \%$ agarose gels, electroeluted, extracted with phenol/chloroform and $5^{\prime}$ labelled with $\left[\gamma^{-32} \mathrm{P}\right] \mathrm{ATP}$ as outlined for oligonucleotides (see above). Samples $(0.2 \mu \mathrm{g})$ of each of these labelled fragments were mixed with $150 \mu \mathrm{g}$ total cellular RNA, precipitated with ethanol and dissolved in $30 \mu 1$ hydridization buffer II $(80 \%$ formamide $/ 40 \mathrm{~mm}$-PIPES $\mathrm{pH} 7.4 / 1 \mathrm{~mm}-\mathrm{EDTA} / 0 \cdot 4 \mathrm{M}-\mathrm{NaCl})$ at $60{ }^{\circ} \mathrm{C}$.

The DNA-RNA hybridization assay was heated to $85^{\circ} \mathrm{C}$ for $10 \mathrm{~min}$, and then kept at the hybridization temperature overnight. The hybridization temperature to be used depends on the GC content of the annealing region (SHV-2a, 51.2\%; SHV-2, 46.7\%) and was deduced from Sambrook et al. (1989). Thus, $59^{\circ} \mathrm{C}$ and $52^{\circ} \mathrm{C}$ for SHV-2, and $64^{\circ} \mathrm{C}$ and $55^{\circ} \mathrm{C}$ for SHV-2a were chosen. At the end of hybridization, $300 \mu \mathrm{l}$ ice-cold $\mathrm{S} 1$ nuclease mapping buffer $(0 \cdot 3 \mathrm{M}-\mathrm{NaCl} / 50 \mathrm{~mm}$-sodium acetate $/ 5 \mathrm{mM}-\mathrm{ZnSO}_{4} / 20 \mu \mathrm{g} \mathrm{ml}^{-1}$ fresh denatured calf thymus DNA/750 U S1 nuclease per $\mathrm{ml}$ final volume) was directly added, mixed quickly and transferred to $37^{\circ} \mathrm{C}$ for $2 \mathrm{~h}$. The reaction was stopped by immediate cooling on ice and addition of $80 \mu \mathrm{l}$ stop mixture (4 M-ammonium acetate $/ 50 \mathrm{mm-EDTA} / 50 \mu \mathrm{g} \mathrm{ml}^{-1}$ yeast tRNA), extracted once with phenol/chloroform and precipitated with ethanol. The pellet was dissolved in $4 \mu \mathrm{l}$ TE buffer, $6 \mu$ loading buffer was added and after conventional denaturation loaded onto a sequencing gel in the same way as for the primer extension analysis.

\section{Results}

\section{Northern blot hybridization}

For hybridization to Northern blots loaded with identical amounts of total cellular RNA of $E$. coli DH5 $\alpha$ transformed with the SHV-2 and SHV-2a genes cloned into pBGS18 (pBP60-1-2 and pZMP1-1-1, respectively) a mixture of three intragenically annealing oligonucleotides (Fig. $1 a$ ) was selected as a probe. Comparing the major signal on the blot of the $\lambda$ DNA/HindIII size standard, the length of the specific transcript was estimated as approximately $1.6 \mathrm{~kb}$. Densitometric evaluation of the hybridization bands indicated an approximately four to five times stronger signal from the SHV-2a RNA.

\section{RNA dot-dot hybridization}

Total cellular RNA from E. coli transformants harbouring the recombinant plasmids pBP60-1-2 (SHV-2) and pZMP1-1-1 (SHV-2a) was serially diluted in twofold steps and dot-blotted onto the nylon membrane. The highest amount of blotted RNA was $40 \mu \mathrm{g}$ in both cases. The mixture of intragenically annealing oligonucleotides (Fig. $1 a$ ) was again used as detection probe. The results are shown in Fig. 2. A signal clearly above background could be detected with $1.25 \mu \mathrm{g}$ blotted total cellular RNA in the case of SHV-2, compared to 0.32 to $0.16 \mu \mathrm{g}$ in the case of SHV-2a. Thus, in the preparation of total cellular RNA containing the SHV-2a mRNA there was about four to eight times more of the specific transcript compared to that of SHV-2.

\section{Promoter mapping of the SHV-2 and SHV-2a genes}

Promoter mapping was achieved by the use of two different methods, primer extension analysis and $\mathrm{S} 1$ nuclease digestion. The three different primers used for the primer extension analysis are shown in Fig. $1(b)$.

As a control for irregularities in the sequencing gels, each individual assay as well as each sequencing reaction as a size standard was loaded onto the gel twice in one run, at different times.

Reverse transcription of the mRNA templates led to identical results irrespective of the primer chosen. S1 nuclease digestion was only effective in the case of the lower hybridization temperatures. The transcription start points defined by primer extension analysis and by S1 nuclease mapping were in excellent agreement.

As examples, representative regions of the sequencing gels loaded with reaction mixtures from primer extension and S1 nuclease assays are shown in Figs 3 and 4, respectively. The transcription start point (position +1 ) for the SHV-2 gene was mapped 100 nucleotides in front of the translation start codon ATG; that of SHV-2a was mapped 50 nucleotides in front of ATG. The alignment of the SHV-2 and SHV-2a sequences upstream of the start codons and the deduced sequences of the corresponding -35 and -10 boxes are shown in Fig. 5 .

\section{Selected PCR-mediated amplification and cloning of the $S H V-2$ and $S H V-2 a$ promoters and SHV-2 structural gene; determination of MICs of resulting recombinant clones}

Two DNA fragments of 510 nucleotides, including the SHV-2 and SHV-2a gene promoters, respectively, were successfully amplified by PCR using the primers shown in Fig. $1(c)$ and both were cloned separately into pBGS19 via restriction sites for EcoRI ( $5^{\prime}$ end) and BamHI ( $3^{\prime}$ end) added to the $5^{\prime}$ ends of the PCR primers. The BamHI site lies between the Shine-Dalgarno sequence and the start codon of the gene and is created by introducing three point mutations in this stretch of sequence. Positive recombinant clones were initially spotted by white/blue selection and subsequently after colony blotting by hybridization with oligonucleotide no. I in Fig. 1(b). Effective cloning was confirmed and unwanted mutations introduced by the PCR reaction were excluded by sequencing these recombinant clones 
(a) Oligonucleotides used as hybridization probes annealing to sequences within the SHV-2 structural gene

I

5' GCG CCG CAG AGC ACT ACT TT 3'

nt. pos. no. $1154-1135$ in SHV-2

II 5' AAT CCT GCG GGG CCG CCG AC 3'

nt. pos. no. $1361-1342$ in SHV-2

III

5' TTG CTG ATT TCG CTC GGC CA 3'

nt. pos. no. $1746-1727$ in SHV-2

(b) Oligonucleotides used in primer extension analysis

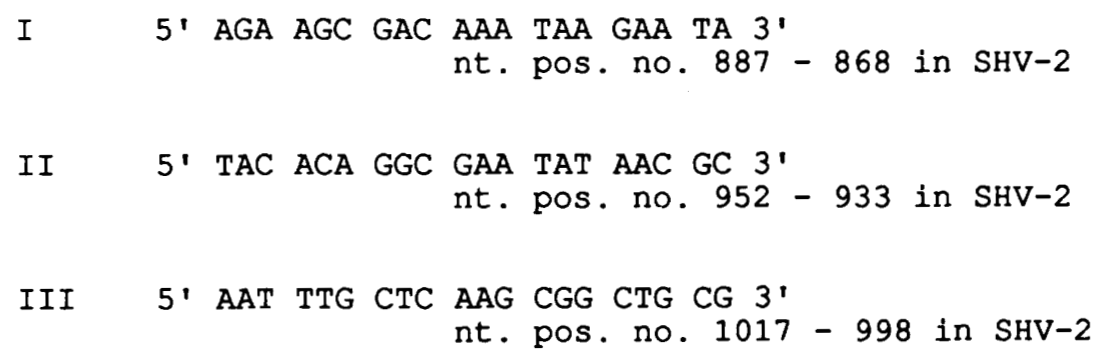

(c) Oligonucleotides used as primers for selective PCR amplification of SHV-2 and SHV-2a promoters and SHV-2 structural gene

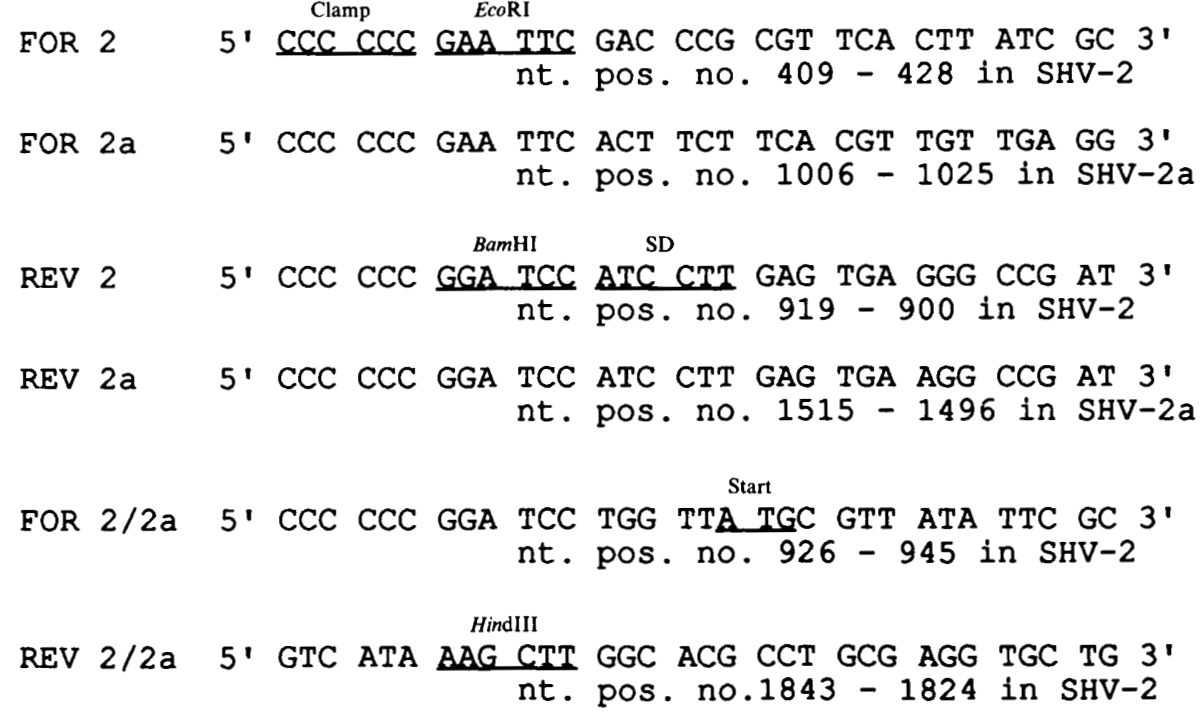

Fig. 1. Sequences of oligonucleotides used in this study for hybridization and primer extension experiments. The purpose of additional nucleotides added to the $5^{\prime}$ end of a specific oligonucleotide or special features within a given oligonucleotide are shown above the region of interest (SD, Shine-Dalgarno sequence; Start, translation start codon). Nucleotide position numbers (nt. pos. no.) refer to the complete SHV-2 and SHV-2a nucleotide sequences. For comparison: the start codons of the SHV-2 and SHV-2a genes comprise nucleotide positions no. 931-933 and 1527-1529, respectively, in the published total sequences (Podbielski \& Melzer, 1990; Podbielski et al., 1991). 


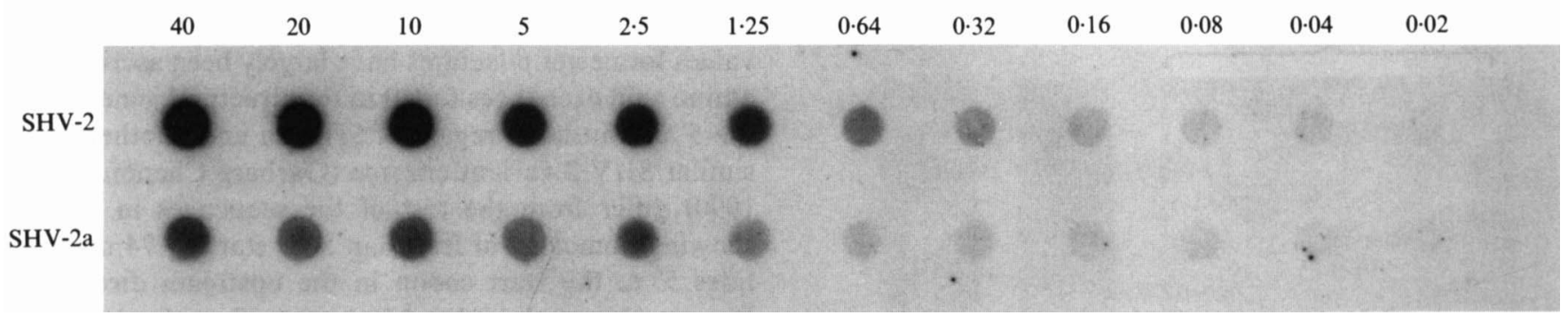

Fig. 2. Hybridization of intragenically annealing oligonucleotides to dot-blotted serial dilutions of SHV-2 and SHV-2a mRNA. The amounts $(\mu \mathrm{g})$ of dot-blotted total cellular RNA are shown above the photograph. For hybridization a mixture of radioactively labelled oligonucleotides (Fig. 1a) was used.

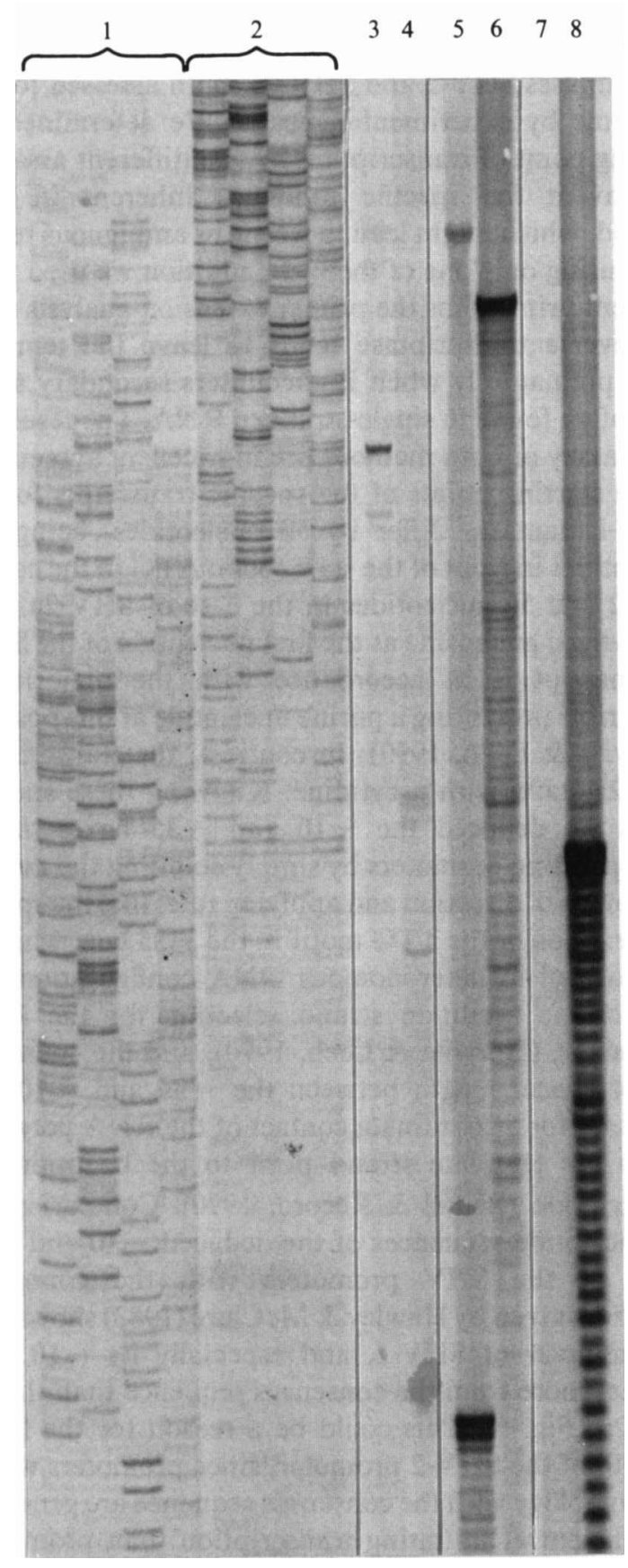

on one strand prior to further recombination experiments. Cloning of the SHV-2 structural gene followed the procedures outlined above, using artificial BamHI ( $5^{\prime}$ end) and HindIII ( $3^{\prime}$ end) restriction sites for cloning, and the mixture of oligonucleotides of Fig. 1 (a) for screening in colony blot hybridization thereafter.

The recombinant plasmids containing the SHV-2 or SHV-2a promoters or the SHV-2 structural gene were designated pZMP2-P, pZMP2a-P and pZMP2-S, respectively. The SHV-2 gene was cut out of pZMP2-S by $B a m \mathrm{HI}$ and HindIII digestion and after separation and cleaning of the fragment was cloned into the corresponding sites of pZMP2-P and pZMP2a-P. E. coli transformants harbouring the new recombinant plasmid were selected on DST agar supplemented with ampicillin or cefotaxime. Plasmid DNA of cefotaxime-resistant clones was analysed by triple digestion with $B a m H I$, EcoRI and HindIII and confirmed to contain the desired compound genes by DNA sequencing.

Five clones each harbouring the recombinant plasmids designated pZMP2-P/2-S (SHV-2 promoter and structural gene) and pZMP2a-P/2-S (SHV-2a promoter and SHV-2 structural gene) were subjected to MIC determination for a panel of $\beta$-lactams. The mean values are presented in Table 1. Recipient E. coli DH5 $\alpha$ devoid of any plasmid was tested in parallel and proved to exhibit MIC values as already published (Podbielski et al., 1991; data not shown).

\section{Discussion}

The first description of a promoter of a chromosomally encoded SHV type $\beta$-lactamase, LEN-1, was by Arakawa et al. (1986). However, these authors did not

Fig. 3. Example of a primer extension analysis for the assessment of the transcription start point of SHV-2a mRNA. Lane 1, sequencing assay as size reference; lanes 3,5 and 7, extension of primers I, III and II (Fig. $1 b$ ), respectively, using SHV-2a mRNA as a template; lanes 2, 4,6 and 8 , each reaction mixture loaded onto the gel for a second time $1.5 \mathrm{~h}$ after starting the first run. 


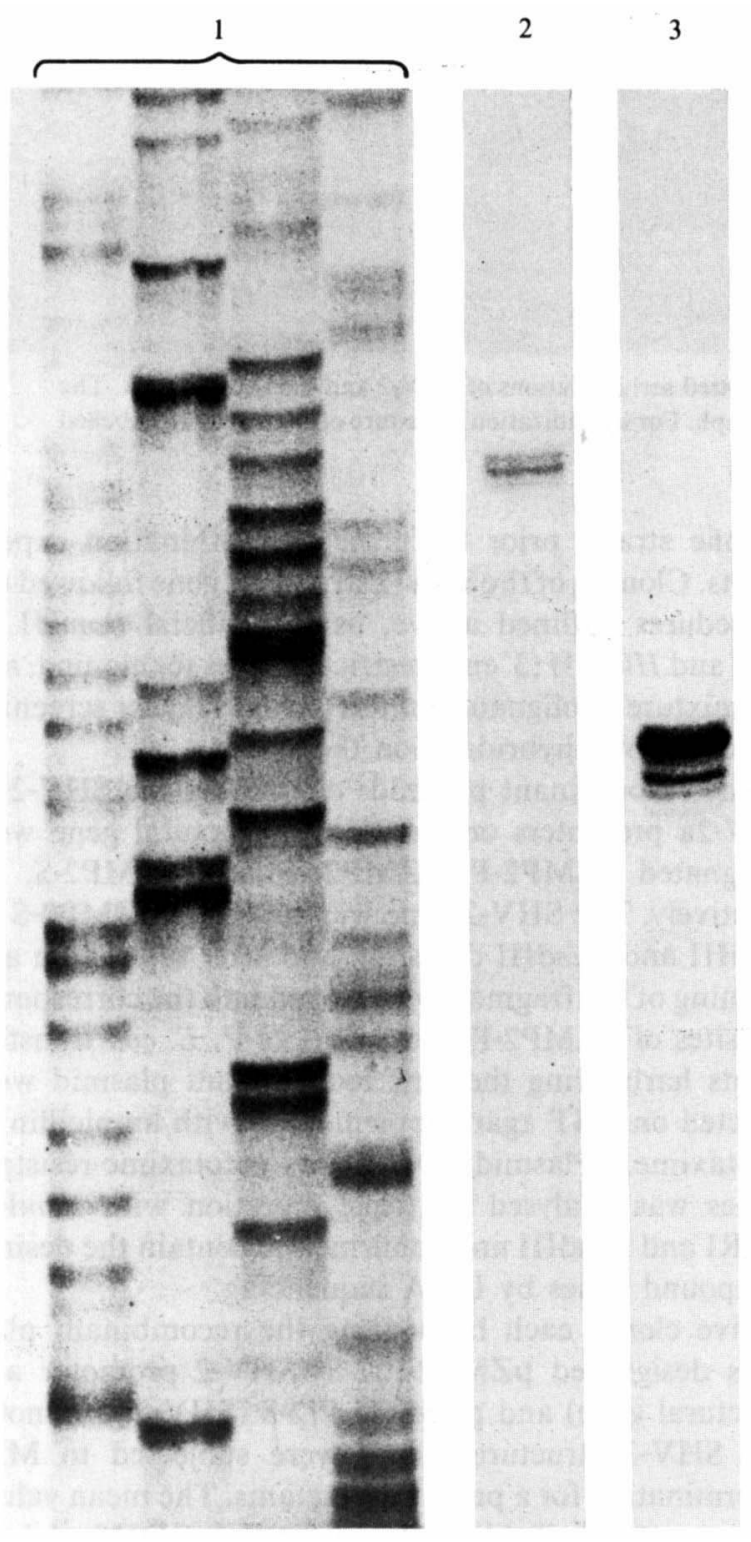

Fig. 4. Example of an $\mathrm{S} 1$ nuclease digestion assay for the assessment of the transcription start point of SHV-2 and SHV-2a mRNA. Lane 1, sequencing assay as size reference; lanes 2 and 3, SHV-2 and SHV-2a mRNA-derived products, respectively. In both assays an SHV-2aderived DNA fragment was used for annealing. Thus, the hybrid with SHV-2 mRNA is only 22 nucleotides longer than the SHV-2a mRNAderived fragment, reflecting the dissimilarity of the two sequences beyond this point.

elaborate in detail how they came to the conclusion that the described nucleotide sequences belong to the promoter. All other groups who later published new nucleotide sequences of plasmid-coded SHV $\beta$-lactamases cited the study of Arakawa et al. (1986) when mentioning a putative promoter site. Since almost all nucleotide sequences adjacent to the $5^{\prime}$ end of a given
SHV gene are highly homologous, differences in MIC values for newer $\beta$-lactams have largely been ascribed to amino acid exchanges found in the structural gene. Only the $5^{\prime}$ untranslated region of SHV-2a and another very similar SHV-2 variant enzyme (Garbarg-Chenon et al., 1990) differ from the rest of the sequences in so far showing homology of less than $50 \%$ starting 74 nucleotides $5^{\prime}$ to the start codon in the upstream direction. Because the much higher MIC values for cefotaxime of the original Klebsiella pneumoniae producers of SHV-2a compared to those harbouring SHV-2 did not correspond with the similar kinetic values of the SHV-2 and SHV-2a enzymes, we decided to analyse the promoters involved.

In this paper we present the different promoters of the $\beta$-lactamases SHV- 2 and SHV-2a, both assessed for the first time by experimental means. We determined the starting point of transcription by two different assays to circumvent the specific problems inherent in each method, which might lead to wrong or ambiguous results when using only one of them. In addition we used three different primers for the primer extension analysis since the reverse transcriptase tends to leave the template stand prematurely when it encounters secondary structures often found in single-stranded RNA. The results by every assay of both methods are in excellent agreement.

The starting points of the specific transcripts for the two $\beta$-lactamases differ by 50 nucleotides, being 100 nucleotides in front of the start codon ATG in the case of SHV-2 and 50 nucleotides in the case of SHV-2a.

Having a guanosine as the first nucleotide of the SHV2 transcript is in accordance with the majority of transcripts presenting a purine nucleotide at this position (Horwitz \& Loeb, 1990); in contrast, the transcript of SHV-2a starts with a cytidine. Knowing these starting points we deduced the -10 and -35 boxes of the corresponding promoters by simply counting the nucleotides in the $5^{\prime}$ direction and applying rules like the special conservation of the TTG motif in the -35 box, which is said to lead to heteronomous DNA configuration and therefore to facilitate strand selection for the RNA polymerase (Horwitz \& Loeb, 1990), and the conservation of spacer length between the -35 and -10 box necessary for a coordinate contact of the RNA polymerase to the template strand prior to the beginning of transcription (Beutel \& Record, 1990). Comparison of the nucleotide sequences of the deduced -10 and -35 boxes of the SHV promoters with the consensus sequences given by Hawley \& McClure (1983) shows that the promoter of SHV-2, and especially its -10 box, deviates more from the consensus sequence than that of SHV-2a (Fig. 5). This could be a reason for the lower strength of the SHV-2 promoter, since promoters which lack homology with the consensus sequence are generally less efficient at initiating transcription than promoters 


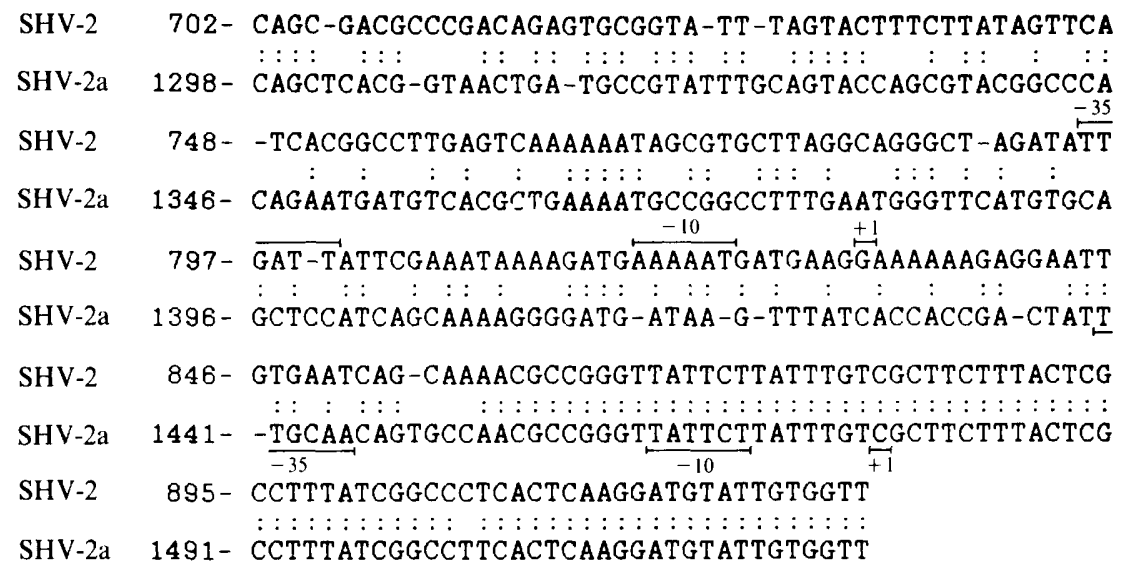

Fig. 5. Alignment of the nucleotide sequences immediately upstream of the start codons of the SHV-2 and SHV-2a $\beta$ lactamase genes. Nucleotide position numbers for the first nucleotide of each line are according to the published sequences of the SHV-2 and SHV-2a genes (Podbielski \& Melzer, 1990; Podbielski et al., 1991), respectively. Lines and numbers above or below a sequence mark the -35 and -10 box of the promoter and the transcription start point of each gene.

Table 1. Mean MIC values for selected $\beta$-lactams of five E. coli transformants each harbouring $p Z M P 2-P / 2-S$ and $p Z M P 2 a-P / 2-S$

pZMP2-P/2-S and pZMP2a-P/2-S are the recombinant plasmids containing the SHV-2 structural gene and the SHV-2 or SHV2a promoter, respectively. For comparison, the corresponding MIC values of $E$. coli transformants harbouring pZMP1-1-1 (SHV-2a; Podbielski et al., 1991) and pBP60-1-2 (SHV-2; Kliebe et al., 1985) are shown. ND, Not determined.

\begin{tabular}{lcccc}
\hline & \multicolumn{4}{c}{ MIC value $\left(\mathrm{mg} \mathrm{l}^{-1}\right)$} \\
\cline { 2 - 4 }$\beta$-Lactam & $\mathrm{pZMP2a-P/2-S}$ & $\mathrm{pZMP2-P} / 2-\mathrm{S}$ & $\mathrm{pZMP1-1-1}$ & $\mathrm{pBP60-1-2}$ \\
\hline Ampicillin & $>128$ & $>128$ & $>128$ & $>128$ \\
Mezlocillin & $>128$ & $>128$ & $>128$ & $>128$ \\
Amoxycillin/ & & & & ND \\
clavulanic acid & $8 / 4$ & $>32$ & $8 / 4$ & $>32$ \\
Cefazolin & $>32$ & 8 & 64 & 4 \\
Cefotaxime & 64 & 4 & 16 & 4 \\
Ceftriaxone & 32 & $\leq 1$ & 8 & 2 \\
Ceftazidime & 4 & $\leq 0 \cdot 5$ & $\leq 0 \cdot 5$ & 1 \\
Imipenem & 1 & $\leq 1$ & 2 & $\leq 1$ \\
Aztreonam & 4 & & & \\
\hline \hline
\end{tabular}

with a high degree of homology (Rosenberg \& Court, 1979; Hawley \& McClure, 1983; Kobayashi et al., 1990). The lower homology of the SHV-2 promoter to the consensus sequence and the simultaneous presence of potential promoter sequences at the position corresponding to the SHV-2a promoter exhibiting a higher degree of homology explains why a computer search for potential promoter sites on the SHV-2 DNA may fail. Even if present, this site is not used for the start of transcription of SHV-2 mRNA, because there is no evidence for a second transcript of different length, in the case of either SHV-2 mRNA or SHV-2a mRNA, as judged from the results of primer extension and S1 nuclease digestion assays and the Northern blots even after prolonged exposure. The inactivity of the site given by Arakawa $e t$ al. (1986) as a promoter may be caused by the aberrant length of the spacer region between the potential -35 and -10 boxes: it is one nucleotide longer than the consensus length of 18 nucleotides.

Both promoters and the intervening regions downstream of the start codons show no significant similarity to those of the TEM $\beta$-lactamases (Russell \& Bennett, 1981 ), to inducible promoters of chromosomally encoded $\beta$-lactamases (Lindberg \& Normark, 1986; Forsman et $a l ., 1989)$ or to regulatory sequences sensitive to heatlabile protein, which may couple the $\beta$-lactamase expression to the SOS response (Kuriki, 1989).

Starting $178 \mathrm{bp}$ downstream of the stop codon of the SHV genes, there is a 318 bp open reading frame of unknown function perfectly conserved in all SHV nucleotide sequences published so far. Considering the starting points of transcription and the length of the specific transcripts, SHV mRNAs may be polycistronic, because they include this open reading frame. 
The PCR-mediated cloning of the different SHV promoters and of the structural gene of SHV-2 and the subsequent recombinant cloning of both promoters in front of the $\beta$-lactamase gene could only be achieved by creating a restriction site, here between the ShineDalgarno sequence and the start codon, via the introduction of three point mutations. The resulting potential hairpin structure may influence the efficiency of transcription or translation by an attenuation process (Lindberg \& Normark, 1986; Lovett, 1990; de Smit \& van Duin, 1990). But we think we can exclude any influences of the manipulations we made with these sensitive parts of the genes, because: $(a)$ the clones containing the SHV-2 promoter/SHV-2 structural gene combination exhibit nearly the same MIC values for $\beta$ lactams as those harbouring the complete natural gene cloned into the same vector plasmid; and $(b)$ the numerical difference of the amount of specific mRNA produced by bacteria transformed with recombinant plasmids containing the complete SHV-2 and SHV-2a genes, respectively, is in the same range as the difference of the MIC values, especially for cefotaxime, of $E$. coli transformants harbouring the PCR-derived substructures of the genes.

On the other hand we cannot exclude the influence of upstream regulatory sequences like those described by Urabe et al. (1990) because the amplified promotercontaining DNA fragments are long enough to comprise such regions and the sequences 500 to $300 \mathrm{bp}$ upstream of the start codon are diverse, so they may exert different influences on the downstream promoters. This influence would have to be caused by cis-acting elements, because we did not amplify the open reading frame situated upstream of the SHV-2a $\beta$-lactamase gene (1135 to 899 nucleotides in front of the start codon; there is none in front of the SHV-2 gene). The method of selective PCR amplification of potential regions of interest on the DNA and their successive combined cloning to functional structures that we employed in this study may serve to answer such questions in future.

In conclusion, we have demonstrated by in vitro and in vivo experiments an alternative means of quantitative adaptation of a plasmid-borne $\beta$-lactamase to confer upon its Klebsiella host a higher level of resistance to a third-generation cephalosporin. The different promoter of SHV-2a alone is sufficient to generate the increased level of resistance to cefotaxime found in bacteria producing SHV-2a. This was confirmed by testing the in vivo effect of the different promoters in front of the same structural gene in otherwise identical host bacteria. This study documents that when looking for the reason for increased in vivo activity of a bacterial isolate against a given substrate, in some cases it may be insufficient to concentrate solely on small mutations of the structural gene of the enzyme, thereby overlooking changes in the regulatory domains.

\section{References}

Aiba, H., Adhya, S. \& De Crombrugghe, B. (1981). Evidence of two functional gal promoters in intact Escherichia coli cells. Journal of Biological Chemistry 256, 11905-11910.

arakawa, Y., Ohta, M., Kido, N., Fujil, Y., Komatsu, T. \& Kato, N. (1986). Close evolutionary relationship between the chromosomally encoded $\beta$-lactamase gene of Klebsiella pneumoniae and the TEM $\beta$-lactamase gene mediated by R plasmids. FEBS Letters 207 , 69-74.

BEUTEL, B. A. \& RECORD, M. T. (1990). E. coli promoter spacer regions contain non-random sequences which correlate to spacer length. Nucleic Acids Research 18, 3597-3603.

Chen, S. T. \& Clowes, R. C. (1984). Two improved promoter sequences for the $\beta$-lactamase expression arising from a single basepair substitution. Nucleic Acids Research 12, 3219-3234.

CHEN, S. T. \& Clowes, R. C. (1987). Variations between the nucleotide sequences of $\operatorname{Tn} 1, \operatorname{Tn} 2$ and $\operatorname{Tn} 3$ and expression of $\beta$-lactamase in Pseudomonas aeruginosa and Escherichia coli. Journal of Bacteriology 169, 913-916.

Collatz, E., Tran Van Nhieu, G., Billot-Klein, D., Williamson, R. \& GuTMANN, L. (1989). Substitution of serine for arginine in position 162 of TEM-type $\beta$-lactamases extends the substrate profile of mutant enzymes, TEM-7 and TEM-101, to ceftazidime and aztreonam. Gene 78, 349-354.

Davis, G. L., Dibner, M. D. \& BAtTey, J. F. (1986). Basic Methods in Molecular Biology. New York: Elsevier.

Forsman, M., Lindgren, L., HÄGgSTröm, B. \& JAURIN, B. (1989). Transcriptional induction of Streptomyces cacaoi $\beta$-lactamase by a $\beta$ lactam compound. Molecular Microbiology 3, 1425-1432.

Garbarg-Chenon, A., Godard, V., Labia, R. \& Nicolas, J. C. (1990). Nucleotide sequence of SHV-2 $\beta$-lactamase gene. Antimicrobial Agents and Chemotherapy 34, 1444-1446.

HaNAHAN, D. (1983). Studies on transformation of Escherichia coli with plasmids. Journal of Molecular Biology 166, 557-589.

HAWley, D. K. \& MCCluRe, W. R. (1983). Compilation and analysis of Escherichia coli promoter DNA sequences. Nucleic Acids Research 11, 2237-2255.

HoRwITZ, M. S. Z. \& LOEB, L. A. (1990). Structure-function relationship in Escherichia coli promoter DNA. In Progress in Nucleic Acid Research and Molecular Biology, vol. 38, pp. 137-164. Edited by W. E. Cohn \& K. Moldave. San Diego: Academic Press.

INOUE, T. \& CECH, T. R. (1985). Secondary structure of the circular form of the Tetrahymena rRNA intervening sequence: a technique for RNA structure analysis using chemical probes and reverse transcriptase. Proceedings of the National Academy of Sciences of the United States of America 82, 648-652.

Kliebe, C., Nies, B. A., Meyer, J. F., TolxdorfF-Neutzling, R. M. \& WIEDEMANN, B. (1985). Evolution of a plasmid-coded resistance to broad spectrum cephalosporins. Antimicrobial Agents and Chemotherapy 28, 302-307.

Kobayashi, M., Nagata, K. \& Ishihama, A. (1990). Promoter selectivity of Escherichia coli RNA polymerase: effect on base substitutions in the promoter -35 region on promoter strength. Nucleic Acids Research 18, 7367-7372.

KURIKI, Y. (1989). The translation start signal region of TEM $\beta$ lactamase mRNA is responsible for heat shock-induced repression of amp gene expression in Escherichia coli. Journal of Bacteriology 171, 5452-5457.

Labia, R., Morand, A., Tiwari, K., Sirot, J., Sirot, D. \& Petit, A. (1988). Interactions of new plasmid-mediated $\beta$-lactamases with third-generation cephalosporins. Reviews of Infectious Diseases 10 , 885-891.

LiNDBERG, F. \& Normark, S. (1986). Contribution of chromosomal $\beta$ lactamases to $\beta$-lactam resistance in Enterobacteria. Reviews of Infectious Diseases 8, Suppl., 292-304. 
LOVETT, P. S. (1990). Translational attenuation as the regulator of inducible cat genes. Journal of Bacteriology 172, 1-6.

MAAs, R. (1983). An improved colony hybridization method with significantly increased sensitivity for detection of single genes. Plasmid 10, 296-298.

Mabilat, C. \& Courvalin, P. (1990). Development of 'oligotyping' for characterization and molecular epidemiology of TEM $\beta$-lactamases in members of the family Enterobacteriaceae. Antimicrobial Agents and Chemotherapy 34, 2210-2216.

Mabilat, C., Goussard, S., Sougakoff, W., Spencer, R. C. \& Courvalin, P. (1990). Direct sequencing of the amplified structural gene and promoter for the extended-broad-spectrum $\beta$-lactamase TEM-9 (RHH-1) of Klebsiella pneumoniae. Plasmid 23, 27-34.

Podbielski, A. \& Melzer, B. (1990). Nucleotide sequence of the gene encoding the SHV-2 $\beta$-lactamase (bla $a_{\mathrm{SHV}-2}$ ) of Klebsiella ozaenae. Nucleic Acids Research 18, 4916.

PoDbielsKi, A., KüHNEMUND, O. \& LÜTTICKEN, R. (1990). Identification of group A type 1 streptococcal $M$ protein gene by nonradioactive oligonucleotide detection method. Medical Microbiology and Immunology 179, 255-262.

Podbielski, A., Schönling, J., Melzer, B., Warnatz, K. \& Leusch, H. G. (1991). Molecular characterization of a new plasmid-encoded SHV-type $\beta$-lactamase (SHV-2 variant) conferring high-level cefotaxime resistance upon Klebsiella pneumoniae. Journal of General Microbiology 137, 569-578.

Reddy, K. J., WebB, R. \& Sherman, L. A. (1990). Bacterial RNA isolation with one hour centrifugation in a table-top ultracentrifuge. Bio Techniques 8, 250-251.
Rosenberg, M. \& CourT, D. (1979). Regulatory sequences involved in the promotion and termination of RNA transcription. Annual Review of Genetics 13, 319-353.

Russell, D. R. \& BeNNETT, G. N. (1981). Characterization of the $\beta$ lactamase promoter of pBR322. Nucleic Acids Research 9, 2517-2533.

Sambrook, J., Fritsch, E. F. \& Maniatis, T. (1989). Molecular Cloning: a Laboratory Manual, 2nd edn. Cold Spring Harbour, NY: Cold Spring Harbor Laboratory.

SANGer, F., Nicklen, S. \& Coulson, A. R. (1977). DNA sequencing with chain-terminating inhibitors. Proceedings of the National Academy of Sciences of the United States of America 74, 5463-5467.

DE SMIT, M. H. \& VAN DUIN, J. (1990). Control of prokaryotic translational initiation by mRNA secondary structure. In Progress in Nucleic Acid Research and Molecular Biology, vol. 38, pp. 1-35. Edited by W. E. Cohn \& K. Moldave. San Diego: Academic Press. SougakofF, W., Goussard, S. \& Courvalin, P. (1988). The TEM-3 $\beta$ lactamase, which hydrolyzes broad-spectrum cephalosporins, is derived from the TEM-2 penicillinase by two amino acid substitutions. FEMS Microbiology Letters 56, 343-348.

Spratt, B. G., Hedge, P. J., Te Heesen, S., Edelmann, A. \& BroomeSMITH, J. K. (1986). Kanamycin-resistant vectors that are analogues of plasmids pUC8, pUC9, pEMBL8 and pEMBL9. Gene 4, 337-342.

Urabe, H., Lenzini, M. V., Mukaide, M., Dusart, J., Nakano, M. M., Ghuysen, J. M. \& Ogawara, H. (1990). $\beta$-Lactamase expression in Streptomyces cacaoi. Journal of Bacteriology 172, 64276434

ZHou, C. Y., YANG, Y. \& JoNG, A. Y. (1990). Miniprep in ten minutes. Bio Techniques 8, 172-173. 